\title{
Utility of Plasma NGAL for the Diagnosis of AKI Following Cardiac Surgery Requiring Cardiopulmonary Bypass: A Systematic Review and Meta-analysis
}

\author{
Hayley Sharrod-Cole ( $\nabla$ hayley.sharrod-cole@nhs.net) \\ Black Country Pathology Services \\ Jonathan Fenn \\ Black Country Pathology Services \\ Rousseau Gama \\ Black Country Pathology Services \\ Clare Ford \\ Black Country Pathology Services \\ Ramesh Giri \\ The Royal Wolverhampton NHS Trust \\ Heyman Luckraz \\ The Royal Wolverhampton NHS Trust
}

\section{Research Article}

Keywords: Plasma NGAL, acute kidney injury, cardiac surgery, cardiopulmonary bypass

Posted Date: November 10th, 2021

DOI: https://doi.org/10.21203/rs.3.rs-995195/v1

License: 두 (i) This work is licensed under a Creative Commons Attribution 4.0 International License. Read Full License

Version of Record: A version of this preprint was published at Scientific Reports on April 19th, 2022. See the published version at https://doi.org/10.1038/s41598-022-10477-5. 


\section{Abstract}

The objective of this study was to assess the diagnostic value of plasma neutrophil gelatinase-associated lipocalin (pNGAL) for the early diagnosis of acute kidney injury (AKI) in adult patients following cardiac surgery requiring cardiopulmonary bypass (CPB). Electronic databases and other resources were systematically searched for relevant studies. Risk of bias was assessed using the Quality Assessment for Diagnostic Accuracy Studies 2 (QUADAS-2) tool. Studies were assigned to a sub-group based on the timing of the pNGAL sample in relation to the cessation of CPB. These were $<4 \mathrm{~h}, 4-8 \mathrm{~h}, 12 \mathrm{~h}$ or $24 \mathrm{~h}$ post-cessation of CPB. Summary values for sensitivity and specificity were estimated using the hierarchical summary receiver operator characteristic (ROC) curve model. A random-effects meta-analysis of each pair of sensitivity and specificity estimates from each included study was performed. In total, 3131 patients from 16 studies were included. When taken at 4-8 hours following CPB, pNGAL had superior performance for the diagnosis of AKI in the defined population when compared to earlier and later time points. Prediction regions and confidence intervals, however, demonstrated significant variability in pooled estimates of sensitivity and specificity. This is likely due to population and study design heterogeneity, lack of standardisation of assays and thresholds, and inability to distinguish the different molecular forms of NGAL. In conclusion, the diagnostic utility of pNGAL in this clinical setting is inconclusive and large individual studies of representative populations of cardiac surgery patients using assays that specifically detect NGAL in its monomeric form are required.

\section{Background}

Acute kidney injury (AKI) is a common complication of cardiac surgery ${ }^{1}$ and is associated with significant mortality, morbidity and increased health care costs. ${ }^{2}$ Studies have reported that AKI, and more specifically AKI requiring renal replacement therapy (RRT) is associated with further increased mortality and longer intensive care unit (ICU) and total hospital length of stay (LOS). ${ }^{3-7}$ Patients undergoing cardiac surgery requiring cardiopulmonary bypass (CPB) are at even greater risk of developing AKI. The mechanism of kidney injury following CPB is multifactorial. Contributing factors include ischemia-reperfusion injury, reduced cardiac output, renal vasoconstriction, CPB hypothermia and rewarming, CPB-induced systemic inflammatory response leading to interstitial inflammation and coagulopathy, which in turn can lead to CPB-related embolization. ${ }^{8-12}$ The reported incidence of post-cardiac surgery AKI varies depending on the definition of AKI and the clinical profile of patients studied. A large meta-analysis reported a rate of CPB associated AKI of $18.2 \%$ which is associated with a greater than 2 -fold increase in mortality. ${ }^{13}$

In clinical practice, the diagnosis of AKI largely relies on the detection of an acute rise in serum creatinine and/or a reduction in urine output, both of which are considered poor markers of AKI. Serum creatinine is affected by many factors including age, sex, race, body surface area, diet, diabetes, liver disease, drugs and laboratory analytical methods which compromise its performance as a diagnostic test for $\mathrm{AKI}^{14}{ }^{14}$ Serum creatinine is a relatively late marker of $\mathrm{AKI}$ and up to $50 \%$ of glomerular function is lost before the serum creatinine is elevated above the reference range. ${ }^{15}$ Neutrophil gelatinase-associated lipocalin (NGAL) is expressed and secreted by kidney cells soon after renal insult, including post-operative ischemia following CPB. NGAL concentrations rise rapidly, within 2-6 hours, and are detectable in plasma when AKI is potentially limitable or reversible. ${ }^{16,17}$ A meta-analysis of 307 studies involving 1,200 patients, reported an area under the curve (AUC) ROC curve value of plasma NGAL (pNGAL) for predicting AKI post-cardiac surgery as 0.78 ( $95 \%$ confidence interval 0.67 to 0.87 ). Plasma NGAL is therefore considered to be a sensitive and specific early marker of AKI and can be detected up to 48 hours before a diagnostic rise in serum creatinine. ${ }^{17} \mathrm{~A}$ meta-analysis of 53 studies with over 7000 patients undergoing cardiac surgery reported that pNGAL was predictive of AKI and its severity, with an AUC ROC curve of $0.82-0.83$. ${ }^{18}$ This meta-analysis did not specifically review a patient cohort undergoing CPB.

In 2018, the AKI-diagnostics project reviewed the diagnostic performance of several potential tests including pNGAL for AKI in an ICU setting. Whilst a subgroup of post cardiac surgery patients was considered, the number of studies included was small and was not specifically defined as cardiac surgery requiring CPB. The review concluded that whilst pNGAL has the potential to add value, results of the analysis were highly uncertain largely due to heterogeneity between studies. ${ }^{19} \mathrm{~A}$ health technology assessment of pNGAL (and other biomarkers) in AKI in critically ill patients in 2019 similarly advised cautious interpretation of results due to heterogeneity between studies but concluded that future studies should evaluate the targeted use of biomarkers such as pNGAL within specific patient populations. ${ }^{20}$ We therefore sought to quantitatively summarize published studies to evaluate the diagnostic accuracy of pNGAL for AKI in a specific clinical setting of adult patients who have undergone cardiac surgery requiring CPB.

\section{Methods}

Page 2/21 
The systematic review was registered with the International Database of Prospectively Registered Systematic Reviews (PROSPERO; registration number CRD42021261676) and conducted in accordance with the PRISMA guideline for reporting of systematic reviews. ${ }^{21}$

\section{Identification of studies}

A comprehensive electronic search was carried out through PubMed, Cochrane database, Scopus, and ClinicalTrials.gov (http://clinicaltrials.gov/) up until June 2021. The search terms used in PubMed were: (heart OR cardiac OR aort* OR valv* OR thoracic) AND surg*) OR 'valve replacement*' OR 'bypass*' OR 'CABG' OR 'extracorporeal circulation' OR 'on pump' OR 'Cardiac Surgical Procedures') AND ('neutrophil gelatinase-associated lipocalin' OR NGAL OR 'LCN2 protein, human') AND ('diagnostic accuracy' OR 'sensitivity' OR 'specificity' OR PPV OR NPV OR 'positive predictive value' OR 'negative predictive value'). In the Cochrane library, Scopus and ClinicalTrials.gov, a similar strategy was used. In addition, abstracts from meetings and reference lists of eligible papers or related reviews were searched manually to identify additional relevant studies.

\section{Inclusion and exclusion criteria}

The inclusion criteria for studies were: (i) adult cardiac surgery cohort requiring CPB; (ii) measurement of plasma NGAL for the early diagnosis of AKI (within $24 \mathrm{~h}$ ) after cardiac surgery; (iii) provision of data from which true-positive (TP), false-positive (FP), falsenegative (FN) and true-negative (TN) could be found or calculated; (iv) AKI clearly defined by acceptable methods- preferably by KDIGO, RIFLE or AKIN criteria ${ }^{22-24}$ and (v) those published in English. Exclusion criteria were: (i) studies with duplicate data reported in other studies; (ii) sample size less than 25; (iii) timing of pNGAL measurement not clearly defined; (iv) inclusion of paediatric patients within the cohort; (v) more than $20 \%$ 'off-pump' patients included in the cohort; (vi) insufficient diagnostic accuracy data available.

\section{Study selection and data extraction}

One reviewer (HSC) screened the titles and abstracts of all citations to judge eligibility based on the inclusion and exclusion criteria. For citations that could not be evaluated through the titles and abstracts, full texts were retrieved for thorough evaluation.

A second reviewer (JF) second checked all prospective citations for eligibility. Full-text copies of all potentially relevant reports were retrieved and assessed for inclusion by both reviewers (HSC and JF).

One reviewer (HSC) extracted the data from each study. This was checked for accuracy by the second reviewer (JF). Any discordance was then checked by the first reviewer. The following information was recorded from each selected study (i) basic characteristics of studies: name of the first author, year of publication, sample size, country; (ii) characteristics of cohort: AKI diagnosis criteria, number of 'off-pump' patients, number of patients who developed AKI; (iii) measurement of NGAL: specimen type, analytical method, NGAL test cut-off and the timing of sample collection; (iv) the criteria for the diagnosis of AKI; (v) study outcomes: test sensitivity and specificity and or true positive (TP), false positive (FP), false negative (FN), true negative (TN), positive predictive value (PPV), negative predictive value (NPV) and area under the receiver operator characteristic curve (AUROC).

\section{Assessment of the risk of bias}

The Quality Assessment of Diagnostic Accuracy Studies version 2 (QUADAS-2) tool was used to assess the risk of bias. ${ }^{25}$ The following items were evaluated: patient selection, interpretation of the index test, appropriateness and interpretation of the reference standard, flow of patients and timing of tests. The applicability of each study to the question under review was also assessed to consider whether the procedures employed in a study would differ significantly from those employed in real clinical practice. Each item was scored as low risk of bias, unclear risk of bias or high risk of bias. Two reviewers (HSC and JF) assessed the risk of bias.

Studies identified to pose a high risk of bias were not excluded from the meta-analysis, but the findings were instead interpreted in light of the bias, which is in keeping with good practice. 


\section{Data Analysis}

For each study, sensitivity, specificity, prevalence, PPV, NPV, TP, FP, FN and TN cases were recorded. If a study lacked the mandatory diagnostic accuracy data, the TP/FP/FN/TN according to the following formulae: sensitivity $=$ TP/ $(T P+F N)$, specificity $=$ TN/ $(F P+$ $\mathrm{TN}), \mathrm{AKI}+$ non-AKI $=\mathrm{TP}+\mathrm{FP}+\mathrm{TN}+\mathrm{FN}$ were calculated and entered into a $2 \times 2$ table.

The diagnostic data were entered into Review Manager software (RevMan version 5.4, Nordic Cochrane Centre, Copenhagen) to generate forest plots of sensitivity and specificity. The odds ratio was used for the synthesis and presentation of results.

To estimate the summary values for sensitivity and specificity, and their $95 \%$ confidence and prediction regions, a random-effects meta-analysis odds ratio (OR) was performed using the hierarchical summary ROC (hSROC) model implemented in STATA $\AA$ software version 16.1 (StataCorp LP, College Station, TX, USA) using the METANDI command. This model is described in the Cochrane Handbook for Systematic Reviews of Diagnostic Test Accuracy for comparisons of test accuracy when there is variability in threshold between studies and is preferred as it takes into account both sensitivity and specificity measures and the correlation between them, assumes that thresholds vary between studies and incorporates variability within and between studies. ${ }^{26}$ In the presence of heterogeneity, which was expected in this review, a random-effects meta-analysis weights the studies relatively more equally than a fixed-effect analysis.

In accordance with the STATA requirements, meta-analyses were performed only when data from four or more studies were available. For studies that reported multiple time points, each was assigned to a group based on the timing of the pNGAL sample in relation to the cessation of CPB. These were $<4 \mathrm{~h}, 4-8 \mathrm{~h} 12 \mathrm{~h}$ or $24 \mathrm{~h}$ post-cessation of CPB. A separate meta-analysis was performed for each time point. Subgroup meta-analysis was also performed based on whether a point of care test (POCT) or laboratory-based method was used.

Heterogeneity was assessed by visual inspection of the forest plots and of the size of the prediction region in the hSROC plots. The index of variability $\left(R^{2}\right)$ statistic and chi-squared test statistic were used to approximate proportion of total variability in point estimates that could be attributed to heterogeneity, although the limitations of this approach are discussed. An $R>50 \%$ with a p-value $<0.05$ from the chi-squared test was indicative of moderate heterogeneity. ${ }^{27}$

\section{Sensitivity Analysis}

Studies identified to have a high risk of bias were individually removed from the meta-analysis and data to determine the effect on the summary points and heterogeneity.

\section{Results}

\section{Summary of included studies}

The literature search yielded 360 records. There were 321 records remaining following removal of duplicates. Following removal of studies that did not meet the inclusion criteria, 39 full text articles were reviewed, and 16 individual studies were included in the final meta-analysis (figure 1). The characteristics of the selected studies are presented in table 1.

Table 1

Included studies 


\begin{tabular}{|c|c|c|c|c|c|c|c|c|c|c|c|c|c|}
\hline $\begin{array}{l}\text { First } \\
\text { author, } \\
\text { year }\end{array}$ & $\begin{array}{l}\text { Assigned } \\
\text { Time } \\
\text { since } \\
\text { CPB } \\
\text { cessation }\end{array}$ & $\begin{array}{l}\text { Sample } \\
\text { size }\end{array}$ & $\begin{array}{l}\text { AKI } \\
\text { Prevalence }\end{array}$ & TP & FP & FN & $\mathrm{TN}$ & $\begin{array}{l}\text { NGAL } \\
\text { cut-off }\end{array}$ & Sens & Spec & PPV & NPV & $\begin{array}{l}\text { AUC } \\
(95 \% \\
\text { Cl) }\end{array}$ \\
\hline \multirow[t]{2}{*}{$\begin{array}{l}\text { Merkle, } \\
201942\end{array}$} & $<4$ & 58 & 0.36 & 15 & 3 & 6 & 34 & $\begin{array}{l}226.98 \\
\mathrm{ng} / \mathrm{mL}\end{array}$ & 0.71 & 0.92 & 0.83 & 0.85 & $\begin{array}{l}0.846 \\
(0.727- \\
0.927)\end{array}$ \\
\hline & 24 & 58 & 0.36 & 18 & 8 & 3 & 29 & $\begin{array}{l}115.87 \\
\mathrm{ng} / \mathrm{mL}\end{array}$ & 0.86 & 0.78 & 0.69 & 0.91 & $\begin{array}{l}0.891 \\
(0.781- \\
0.957)\end{array}$ \\
\hline $\begin{array}{l}\text { Introcaso, } \\
2018^{43}\end{array}$ & $4-8$ & 69 & 0.35 & 18 & 18 & 6 & 27 & $\begin{array}{l}154 \\
\mathrm{ng} / \mathrm{mL}\end{array}$ & 0.76 & 0.59 & 0.5 & 0.81 & $\begin{array}{l}0.71 \\
(0.60- \\
0.82)\end{array}$ \\
\hline $\begin{array}{l}\text { Guerci, } \\
2018^{44}\end{array}$ & $4-8$ & 50 & 0.36 & 15 & 5 & 3 & 27 & $\begin{array}{l}112 \\
\mathrm{ng} / \mathrm{mL}\end{array}$ & 0.83 & 0.84 & 0.75 & 0.9 & $\begin{array}{l}0.9 \\
(0.81- \\
0.98)\end{array}$ \\
\hline \multirow[t]{3}{*}{$\begin{array}{l}\text { Schley, } \\
2015^{45}\end{array}$} & $<4$ & 110 & 0.34 & 28 & 18 & 9 & 55 & $\begin{array}{l}173.43 \\
\mathrm{ng} / \mathrm{mL}\end{array}$ & 0.76 & 0.75 & 0.609 & 0.859 & $\begin{array}{l}0.81 \\
(0.73- \\
0.90)\end{array}$ \\
\hline & $4-8$ & 110 & 0.34 & 29 & 18 & 8 & 55 & $\begin{array}{l}178.20 \\
\mathrm{ng} / \mathrm{mL}\end{array}$ & 0.78 & 0.75 & 0.617 & 0.873 & $\begin{array}{l}0.83 \\
(0.75- \\
0.91)\end{array}$ \\
\hline & 24 & 110 & 0.34 & 32 & 18 & 5 & 55 & $\begin{array}{l}137.61 \\
\mathrm{ng} / \mathrm{mL}\end{array}$ & 0.86 & 0.75 & 0.640 & 0.916 & 0.84 \\
\hline $\begin{array}{l}\text { Park, } \\
201546\end{array}$ & $4-8$ & 112 & 0.12 & 8 & 11 & 5 & 88 & $\begin{array}{l}168.5 \\
\mathrm{ng} / \mathrm{mL}\end{array}$ & 0.62 & 0.89 & 0.421 & 0.946 & $\begin{array}{l}0.81 \\
(0.68- \\
0.95)\end{array}$ \\
\hline $\begin{array}{l}\text { Kidher, } \\
201447\end{array}$ & $<4$ & 53 & 0.30 & 13 & 4 & 3 & 33 & $\begin{array}{l}150 \\
\mathrm{ng} / \mathrm{mL}\end{array}$ & 0.80 & 0.89 & 0.765 & 0.917 & $\begin{array}{l}0.83 \\
(0.70- \\
0.95)\end{array}$ \\
\hline \multirow[t]{2}{*}{$\begin{array}{l}\text { Ghonemy, } \\
2014^{30}\end{array}$} & $4-8$ & 50 & 0.34 & 17 & 3 & 0 & 30 & $\begin{array}{l}62 \\
\mathrm{ng} / \mathrm{dL}\end{array}$ & 0.98 & 0.92 & 0.842 & 0.967 & $\begin{array}{l}\text { Not } \\
\text { stated }\end{array}$ \\
\hline & $<4$ & 50 & 0.34 & 16 & 2 & 1 & 31 & $\begin{array}{l}62 \\
\mathrm{ng} / \mathrm{dL}\end{array}$ & 0.94 & 0.94 & 0.888 & 0.968 & $\begin{array}{l}\text { Not } \\
\text { stated }\end{array}$ \\
\hline $\begin{array}{l}\text { Parikh, } \\
2011{ }^{29}\end{array}$ & $<4$ & 1219 & 0.05 & 30 & 209 & 30 & 950 & $\begin{array}{l}293 \\
\mathrm{ng} / \mathrm{mL}\end{array}$ & 0.50 & 0.82 & 0.126 & 0.969 & $\begin{array}{l}0.7 \\
(S E \\
0.04)\end{array}$ \\
\hline \multirow[t]{2}{*}{$\begin{array}{l}\text { Perry, } \\
201048\end{array}$} & $<4$ & 879 & 0.09 & 29 & 149 & 46 & 655 & $\begin{array}{l}353.5 \\
\mathrm{ng} / \mathrm{mL}\end{array}$ & 0.39 & 0.82 & 0.163 & 0.934 & $\begin{array}{l}0.641 \\
(0.58- \\
0.71)\end{array}$ \\
\hline & 24 & 879 & 0.09 & 42 & 242 & 33 & 562 & $\begin{array}{l}353.5 \\
\mathrm{ng} / \mathrm{mL}\end{array}$ & 0.55 & 0.70 & 0.148 & 0.945 & $\begin{array}{l}0.670 \\
(0.60- \\
0.74)\end{array}$ \\
\hline $\begin{array}{l}\text { Haase, } \\
200949\end{array}$ & $4-8$ & 100 & 0.46 & 34 & 14 & 12 & 40 & $\begin{array}{l}150.0 \\
\mathrm{ng} / \mathrm{mL}\end{array}$ & 0.73 & 0.74 & 0.708 & 0.769 & $\begin{array}{l}0.77 \\
(0.63- \\
0.91)\end{array}$ \\
\hline \multirow[t]{2}{*}{$\begin{array}{l}\text { Haase- } \\
\text { Fielitz, } \\
200918\end{array}$} & $4-8$ & 100 & 0.23 & 18 & 17 & 5 & 60 & $\begin{array}{l}150.0 \\
\mathrm{ng} / \mathrm{mL}\end{array}$ & 0.79 & 0.78 & 0.52 & 0.93 & $\begin{array}{l}0.80 \\
(0.63- \\
0.96)\end{array}$ \\
\hline & 24 & 100 & 0.23 & 21 & 18 & 2 & 59 & $\begin{array}{l}150.0 \\
\mathrm{ng} / \mathrm{mL}\end{array}$ & 0.91 & 0.76 & 0.53 & 0.97 & $\begin{array}{l}0.87 \\
(0.78- \\
0.96)\end{array}$ \\
\hline \multirow[t]{2}{*}{$\begin{array}{l}\text { Perrotti, } \\
2015^{50}\end{array}$} & 24 & 166 & 0.31 & 31 & 27 & 21 & 87 & $\begin{array}{l}258 \\
\mathrm{ng} / \mathrm{mL}\end{array}$ & 0.60 & 0.76 & 0.534 & 0.806 & 0.7 \\
\hline & 12 & 166 & 0.31 & 43 & 48 & 9 & 66 & 173 & 0.82 & 0.58 & 0.473 & 0.88 & 0.7 \\
\hline
\end{tabular}




\begin{tabular}{|c|c|c|c|c|c|c|c|c|c|c|c|c|c|}
\hline & $4-8$ & 166 & 0.31 & 41 & 48 & 11 & 66 & $\begin{array}{l}155 \\
\mathrm{ng} / \mathrm{mL}\end{array}$ & 0.79 & 0.58 & 0.461 & 0.857 & 0.7 \\
\hline & $<4$ & 166 & 0.31 & 28 & 33 & 24 & 81 & $\begin{array}{l}178 \\
\mathrm{ng} / \mathrm{mL}\end{array}$ & 0.54 & 0.71 & 0.459 & 0.771 & 0.6 \\
\hline \multirow[t]{2}{*}{$\begin{array}{l}\text { Gaipov, } \\
2015^{51}\end{array}$} & 12 & 60 & 0.67 & 21 & 5 & 19 & 15 & $\begin{array}{l}199 \\
\mathrm{ng} / \mathrm{mL}\end{array}$ & 0.52 & 0.73 & 0.808 & 0.441 & $\begin{array}{l}0.649 \\
(0.507 \\
0.774)\end{array}$ \\
\hline & 24 & 60 & 0.67 & 32 & 11 & 8 & 9 & $\begin{array}{l}175.4 \\
\mathrm{ng} / \mathrm{mL}\end{array}$ & 0.79 & 0.46 & 0.744 & 0.529 & $\begin{array}{l}0.646 \\
(0.504 \\
0.772)\end{array}$ \\
\hline $\begin{array}{l}\text { Prabhu, } \\
2010^{52}\end{array}$ & $4-8$ & 30 & 0.27 & 8 & 2 & 0 & 20 & $\begin{array}{l}229 \\
\mathrm{ng} / \mathrm{mL}\end{array}$ & 1.00 & 0.91 & 0.794 & 1 & 0.98 \\
\hline $\begin{array}{l}\text { Tuladhar, } \\
2009^{53}\end{array}$ & $<4$ & 50 & 0.18 & 7 & 14 & 2 & 27 & $\begin{array}{l}426 \\
\mathrm{ng} / \mathrm{mL}\end{array}$ & 0.80 & 0.67 & 0.333 & 0.931 & $\begin{array}{l}0.85 \\
(0.73- \\
0.97)\end{array}$ \\
\hline $\begin{array}{l}\text { Othman, } \\
2021^{28}\end{array}$ & $4-8$ & 25 & 0.28 & 7 & 2 & 0 & 16 & $\begin{array}{l}145 \\
\mathrm{ng} / \mathrm{mL}\end{array}$ & 1.00 & 0.89 & 0.778 & 1 & 0.965 \\
\hline
\end{tabular}

A total of 3131 individual patients were included. The studies were split into groups based on the timing of the pNGAL sample; these were $<4 \mathrm{~h}, 4-8 \mathrm{~h} 12 \mathrm{~h}$ or $24 \mathrm{~h}$ post-cessation of CPB. Where this was not clearly stated in the study, a pragmatic approach was taken and agreed by three reviewers (HSC, JF and HL). In the subsequent QUADAS-2 assessment the applicability of the index test to review the question was then judged to be unclear. A total of 8 studies were classified as $<4 \mathrm{~h}$ and included 2585 patients, 10 studies were classified as 4-8 h and included 812 patients, two studies classified as $12 \mathrm{~h}$, and six at $24 \mathrm{~h}$ comprising 1373 patients (Table 2).

Table 2

Summary of included studies

\begin{tabular}{|lll|}
\hline timing of pNGAL sample (hrs since CPB) & number of studies & number of patients \\
\hline$<4$ & 8 & 2585 \\
\hline $4-8$ & 10 & 812 \\
\hline 12 & 2 & 226 \\
\hline 24 & 6 & 1373 \\
\hline
\end{tabular}

\section{Study Quality}

Risk of bias was assessed using the QUADAS-2 tool and summarised in figures 2 and 3. Most studies (94\%) were deemed to be at low risk of bias due to patient selection. One study cohort included only patients who had undergone coronary artery bypass graft (CABG) which may not be representative of all cardiac surgery patients. ${ }^{28}$ The main potential source of bias related to blinding. Most studies were assessed as being either at high risk (44\%) or unclear risk $(31 \%)$ of bias for the conduct or interpretation of the index test largely due to the interpretation of the index test (pNGAL) occurring with prior knowledge of the reference standard results. One study was deemed to be at high risk of bias due to the classification of AKI as a doubling of serum creatinine which would exclude early AKI and explains the lower study prevalence of AKI (4.9\%) compared to other studies. ${ }^{29}$ There were no concerns regarding risk of bias introduced by the flow and timing of samples.

The applicability of patient selection was deemed to be unclear in two studies. In one study, it was not explicitly stated that patients were on $\mathrm{CPB}$, but this was implied in the discussion and conclusions of the paper. ${ }^{30}$ The applicability of the index test to review the 


\section{Diagnostic accuracy of pNGAL for identifying AKI in the defined cohort}

The $12 \mathrm{~h}$ group was excluded from further analysis due to insufficient study numbers. Individual study sensitivities ranged from 0.39 $0.94,0.62-1.00$ and $0.56-0.91$ in the $<4 \mathrm{~h}, 4-8 \mathrm{~h}$, and $24 \mathrm{~h}$ groups respectively. Forest plots of sensitivity and specificity for all studies are presented in figure 4 . The summary estimates of sensitivity were 0.68 ( $95 \% \mathrm{Cl} 0.52-0.8), 0.81(95 \% \mathrm{Cl} 0.74-0.87), 0.78$ (95\% Cl 0.640.87 ) and specificity 0.82 (95\% Cl0.75-0.88), 0.8 (95\% Cl 0.71-0.87), 0.73 (95\% Cl 0.69-0.77) in the < $4 \mathrm{~h}, 4-8 \mathrm{~h}$, and $24 \mathrm{~h}$ groups respectively (Table 3).

Table 3

Summary points and sensitivity analysis

\begin{tabular}{|c|c|c|c|c|c|c|}
\hline time since CPB & description & No studies & sensitivity & $95 \% \mathrm{Cl}$ & specificity & $95 \% \mathrm{Cl}$ \\
\hline$<4 \mathrm{hrs}$ & All studies & 8 & 0.676 & $0.521-0.800$ & 0.822 & $0.753-0.875$ \\
\hline 4-8 hrs & All studies & 10 & 0.814 & $0.743-0.869$ & 0.801 & $0.713-0.868$ \\
\hline 4-8 hrs & Othman, 2021 removed & 9 & 0.802 & $0.734-0.856$ & 0.791 & $0.698-0.860$ \\
\hline 4-8 hrs & Haase, 2009 removed & 9 & 0.831 & $0.752-0.888$ & 0.810 & $0.712-0.880$ \\
\hline $24 \mathrm{hrs}$ & All studies & 6 & 0.776 & $0.638-0.871$ & 0.729 & $0.685-0.769$ \\
\hline $24 \mathrm{hrs}$ & $\begin{array}{l}\text { Perry, } 2010 \\
\text { removed }\end{array}$ & 5 & 0.810 & $0.686-0.893$ & 0.744 & $0.692-0.790$ \\
\hline 4-8 hrs & NGAL ELISA & 4 & 0.986 & $0.362-0.999$ & 0.869 & $0.753-0.935$ \\
\hline 4-8hrs & Triage NGAL & 6 & 0.755 & $0.680-0.818$ & 0.751 & $0.642-0.836$ \\
\hline
\end{tabular}

Summary ROC curves (Figure 5) suggest pNGAL when taken at 4-8 $\mathrm{h}$ post-cessation of CPB to be the optimal test. The 4-8 $\mathrm{h}$ group was, therefore, subjected to in depth analysis. When the method type (Triage NGAL versus NGAL ELISA) was added as a covariate the shape of the summary ROC further improved. However, when the hSROC analysis was applied, the prediction regions indicated a large degree of heterogeneity in both sensitivity and specificity estimates (Table 3). It is worth noting the individual sample sizes in the four studies in this group were small.

Figure 5a-c. a) summary ROC plots with hSROC summary points overlaid, b) summary ROC when method type was added as a covariate, c) summary ROC when method type was added as a covariate with hSROC summary points and prediction regions overlaid.

Figure 6 and 7 a-b show the hSROC for each time point with 95\% confidence region for the summary operating point and 95\% prediction region. At $<4 \mathrm{~h}$, the confidence and prediction regions indicate a greater degree of heterogeneity in sensitivity estimates than in specificity estimates between studies. Specificity estimates were reasonably homogeneous. At 4-8 $\mathrm{h}$, the confidence and prediction regions indicate a greater degree of heterogeneity in specificity estimates than in sensitivity estimates between studies. At 24 hours, specificity estimates were reasonably homogeneous but there was a considerable degree of heterogeneity in the sensitivity estimates.

Figure 7 a-b . a) hSROC of pNGAL taken at 4-8 hours post CPB: left hSROC including all studies and right hSROC following removal of Haase, 2009 study due to possible incorrect subgrouping b) hSROC of pNGAL taken at 24 hours post CPB: left hSROC including all studies and right hSROC following removal of Perry, 2010 study due to high risk of bias

\section{Heterogeneity and covariates}

The between-study variation of the effect sizes is evident from visual inspection of the forest plot. In the $4-8 \mathrm{~h}$ group the $I^{2}$ statistic was $40.6 \%$, indicating mild heterogeneity. ${ }^{27}$ Subgroup analysis based on method type showed that there was no observed heterogeneity in 
the NGAL ELISA group $(R=0 \%)$ and moderate heterogeneity $\left(F^{2}=62.1 \%\right)$ in the Triage NGAL test group. The test of homogeneity of study-specific effect sizes was also rejected in the Triage NGAL test subgroup, with a chi-squared test statistic of 13.02 and a $p$-value of 0.02 (Figure 8).

\section{Publication bias}

Funnel plot asymmetry was evident in the 4-8h group. There was a clear absence of studies in the lower left portion of the plot (Figure 9). Although it should be noted that the number of studies is small and therefore funnel plot asymmetry does not necessarily indicate publication bias.

\section{Discussion}

Our meta-analysis of sensitivity and specificity estimates indicates that pNGAL taken $4-8 \mathrm{~h}$ following cessation of CPB in cardiac surgery patients is superior to pNGAL taken at $<4 \mathrm{~h}$ or $24 \mathrm{~h}$ for the early diagnosis of AKI. This is supported by data from the TRIBE-AKI study which reported that PNGAL concentrations peak at $6 \mathrm{~h}$ post cardiac surgery. ${ }^{29} \mathrm{It}$ was expected that the pooled estimates for sensitivity and specificity would be greater at $24 \mathrm{~h}$, however the number of studies in this group was small. In addition, one study in the $24 \mathrm{~h}$ group was identified as high risk of bias due to the classification of AKI as a doubling of serum creatinine which would exclude early AKI defined by other standard criteria. The bias is supported by the lower prevalence of AKI (4.9\%) compared to reported prevalence of AKI post-cardiac surgery $(18.2 \%) .{ }^{13}$ Exclusion of this study from the meta-analysis improved summary points for sensitivity and specificity but the confidence and prediction regions increased.

The prediction regions and confidence limits at all time points were large due to considerable clinical and statistical heterogeneity observed across studies and the limited number of studies available for subgroup analyses. Surgery type, and patient related risk factors including age, sex, diabetes mellitus, basal renal function and congestive heart failure, contribute to the complex relationship between co-morbid pathophysiology and CPB as major causes of AKI in the population studied. 5,24,31 There was, however, significant variation between individual studies in patient inclusion criteria and risk factors that were included or excluded from the analysis. One study included only CABG procedures whereas others excluded this procedure which is of significance as it is associated with the lowest incidence of AKI post-cardiac surgery. ${ }^{32}$ The importance of comorbidities as confounders is further supported by superior predictive performance in paediatric cohorts, in which co-morbidities are almost invariably absent. ${ }^{17}$

The threshold level for pNGAL varied considerably across studies. Despite this limitation, results across similar studies were pooled since a standardised cut-off for pNGAL has not yet been defined. The variability in thresholds and diagnostic accuracy in the population may in part be due to the complex origin of NGAL. NGAL exists in at least three different molecular forms; a $25 \mathrm{kDa}$ monomer, a $45 \mathrm{kDa}$ homodimer, and a $135 \mathrm{kDa}$ NGAL/matrix metalloproteinase-9 (MMP-9) covalently complexed heterodimer. The renal cells predominantly produce the monomeric form and to lesser extent the heterodimeric form, whereas neutrophils contain all molecular forms. The homodimer is, therefore, specific for neutrophils. ${ }^{33-35}$ The systemic inflammatory response triggered by CPB will activate circulating neutrophils to release their granular contents, including NGAL. Indeed, NGAL concentrations have been shown to be correlated with CPB duration and furthermore it is the homodimeric form that predominates suggesting that neutrophils as opposed to renal cells are the main source. ${ }^{36}$ Various commercially available NGAL assays were utilised in the studies included in this review, several of which were marketed as 'research use only' assays. The NGAL assays cannot distinguish between the molecular forms released by different tissues. There is also currently no standardisation of NGAL assays and the specificity of the assays for the monomeric form was not stated in manufacturer's instructions for use.

The diagnostic utility of pNGAL is inherently flawed when assessed against an imperfect reference standard. Serum creatinine is diluted in fluid-loaded patients; therefore, the incidence of AKI may be underestimated in this cohort. ${ }^{37}$ Elevated NGAL in the absence of creatinine-based criteria for AKI is associated with an increased requirement for RRT and mortality, but it is unclear whether this represents subclinical AKI or severity of the systemic inflammatory response. ${ }^{38,39}$

A large value of $P$ was interpreted as meaning that the effect size varies substantively across studies. The $P$ statistic merely designates the extent of inconsistency of findings across studies in the meta-analysis and reflects the extent to which confidence intervals from the different studies overlap with each other. Univariate tests for heterogeneity in sensitivity and specificity and the estimates of the ${ }^{2}$ statistic are not recommended as they do not account for heterogeneity explained by phenomena such as positivity

Page $8 / 21$ 
threshold effects. ${ }^{27}$ A degree of heterogeneity is inevitable, and it could be argued that any degree of heterogeneity is acceptable provided the protocol is clearly defined and risk of bias has been assessed and findings interpreted considering this.

Tests for funnel plot asymmetry are designed primarily for use in randomized trials and should not be used in systematic reviews of diagnostic test accuracy as there is potential to incorrectly indicate publication bias. ${ }^{26} \mathrm{~A}$ more appropriate method for detecting funnel plot asymmetry in reviews of diagnostic studies has been developed but also has low power when there is heterogeneity in the diagnostic odds ratio, as is present in this study. ${ }^{40}$

The hSROC curves appear to show optimisation of sensitivity at the expense of specificity at 4-8 $\mathrm{h}$ possibly in attempt to rule-in AKI earlier whereas at $24 \mathrm{~h}$ there is considerably more variability in sensitivity, perhaps indicating optimisation of specificity i.e., a rule out approach. It is noted that in the individual studies there is seldom an explanation of how the optimal cut-off point for pNGAL was reached. We suggest that it may be more appropriate to assess the utility of pNGAL as a rule out test in this population. The NICE diagnostics assessment programme manual however does not recommend the separate analysis of negative and positive predictive values as this approach fails to take into account the correlation between the two parameters. In addition, pooled analysis of NPV or PPV is not recommended because of the impact of disease prevalence on these parameters, which is likely to vary between studies. ${ }^{41}$ Therefore, larger prospective studies or randomised controlled trials (RCTs) in a representative population are required.

\section{Limitations}

The limitations of the meta-analysis are largely due to between study heterogeneity. Although risk of bias was assessed, and results of the meta-analysis were interpreted accordingly, the risk of bias in many cases was classified as unclear. Often measurement procedures performed within the studies differed significantly from those employed in routine practice, typically for reasons of pragmatism or cost. Many studies, for example, reported that samples were frozen and analysed as a single batch. The impact of analysing samples within a single batch is that it reduces variance increasing the likelihood of a significant finding. However, the results then may not translate to clinical practice, where samples are measured over many days and using different batches of reagents. The effect of freeze-thawing is also seldom stated, and this may be a potential source of a systematic increase or decrease in biomarker concentration. This could render clinical cut-off points invalid and lead to a higher FP or FN rate when introduced into routine practice. There was also, as previously discussed, significant heterogeneity in the characteristics of patients included in the studies.

Although the use of QUADAS-2 addresses the methodological issues concerning diagnostic accuracy, it does not address the issues associated with measurement. There are currently no guidelines available for evaluating the quality of measurement procedures in diagnostic accuracy studies. Therefore, this is an accepted limitation of the meta-analysis.

\section{Conclusions}

Whilst there is a potential role for the diagnostic utility of pNGAL in this clinical setting, because of the limited number of studies, substantial heterogeneity between studies and large $95 \%$ confidence and prediction regions, reliable conclusions cannot be drawn. There is currently no standardisation of assays or thresholds, and the assays included in this analysis cannot distinguish between the various molecular forms of NGAL released by different tissues. Larger prospective studies or RCTs, ideally distinguishing the monomeric form of NGAL, in a population truly representative of those undergoing cardiac surgery requiring $\mathrm{CPB}$, are required.

\section{Abbreviations}

AKI Acute kidney injury

AKIN Acute kidney injury network

AUC Area under curve

Cl Confidence interval 
CABG Coronary artery bypass graft

CPB Cardio-pulmonary bypass

DAP Diagnostics Assessment Programme

FN False negative

FP False positive

hSROC Hierarchical summary receiver operator characteristic

ICU Intensive care unit

KDIGO Kidney Disease: Improving Global Outcomes

LOS Length of stay

NGAL Neutrophil gelatinase-associated lipocalin

NICE National Institute for Health and Care Excellence

NPV Negative predictive value

PPV Positive predictive value

QUADAS 2 Quality assessment of diagnostic accuracy studies version 2

ROC Receiver operator characteristic

RIFLE Risk, Injury, Failure, Loss of kidney function and End-stage kidney disease

RRT Renal replacement therapy

TN True negative

TP True positive

\section{Declarations}

\section{Ethics approval and consent to participate}

Not applicable

\section{Consent for publication}

Not applicable

\section{Availability of data and materials}

All relevant data generated or analysed during this study are included in this published article.

\section{Competing interests}

The authors declare that they have no competing interests. 


\section{Funding}

Not applicable

\section{Authors' contributions}

HSC and JF reviewed all articles included in this meta-analysis and performed the data analysis. HL acted as an additional reviewer where stated. HSC drafted the initial manuscript. All authors read and approved the final manuscript.

\section{Acknowledgements}

Not applicable

\section{References}

1. Hoste EA, Cruz DN, Davenport A, et al. The epidemiology of cardiac surgery-associated acute kidney injury. Int J Artif Organs. Feb 2008;31(2):158-65. doi:10.1177/039139880803100209

2. Hoste EA, Bagshaw SM, Bellomo R, et al. Epidemiology of acute kidney injury in critically ill patients: the multinational AKI-EPI study. Intensive Care Med. Aug 2015;41(8):1411-23. doi:10.1007/s00134-015-3934-7

3. Mishra PK, Luckraz H, Nandi J, et al. Long-term quality of life postacute kidney injury in cardiac surgery patients. Ann Card Anaesth. Jan-Mar 2018;21(1):41-45. doi:10.4103/aca.ACA_104_17

4. Luckraz $\mathrm{H}$, Gravenor MB, George R, et al. Long and short-term outcomes in patients requiring continuous renal replacement therapy post cardiopulmonary bypass. Eur J Cardiothorac Surg. May 2005;27(5):906-9. doi:10.1016/j.ejcts.2005.01.057

5. Chertow GM, Burdick E, Honour M, Bonventre JV, Bates DW. Acute kidney injury, mortality, length of stay, and costs in hospitalized patients. J Am Soc Nephrol. Nov 2005;16(11):3365-70. doi:10.1681/asn.2004090740

6. Coca SG, Yusuf B, Shlipak MG, Garg AX, Parikh CR. Long-term risk of mortality and other adverse outcomes after acute kidney injury: a systematic review and meta-analysis. Am J Kidney Dis. Jun 2009;53(6):961-73. doi:10.1053/j.ajkd.2008.11.034

7. Hobson CE, Yavas S, Segal MS, et al. Acute kidney injury is associated with increased long-term mortality after cardiothoracic surgery. Circulation. May 12 2009;119(18):2444-53. doi:10.1161/circulationaha.108.800011

8. Boldt J, Brenner T, Lehmann A, Suttner SW, Kumle B, Isgro F. Is kidney function altered by the duration of cardiopulmonary bypass? Ann Thorac Surg. Mar 2003;75(3):906-12. doi:10.1016/s0003-4975(02)04559-9

9. Ranucci M, Pavesi M, Mazza E, et al. Risk factors for renal dysfunction after coronary surgery: the role of cardiopulmonary bypass technique. Perfusion. 1994;9(5):319-26. doi:10.1177/026765919400900503

10. Boodhwani M, Rubens FD, Wozny D, Nathan HJ. Effects of mild hypothermia and rewarming on renal function after coronary artery bypass grafting. Ann Thorac Surg. Feb 2009;87(2):489-95. doi:10.1016/j.athoracsur.2008.10.078

11. Paparella D, Yau TM, Young E. Cardiopulmonary bypass induced inflammation: pathophysiology and treatment. An update. Eur $J$ Cardiothorac Surg. Feb 2002;21(2):232-44. doi:10.1016/s1010-7940(01)01099-5

12. Sreeram GM, Grocott HP, White WD, Newman MF, Stafford-Smith M. Transcranial Doppler emboli count predicts rise in creatinine after coronary artery bypass graft surgery. J Cardiothorac Vasc Anesth. Oct 2004;18(5):548-51. doi:10.1053/j.jvca.2004.07.010

13. Pickering JW, James MT, Palmer SC. Acute kidney injury and prognosis after cardiopulmonary bypass: a meta-analysis of cohort studies. Am J Kidney Dis. Feb 2015;65(2):283-93. doi:10.1053/j.ajkd.2014.09.008

14. Delanaye P, Cavalier E, Pottel H. Serum Creatinine: Not So Simple! Nephron. 2017;136(4):302-308. doi:10.1159/000469669

15. Liu KD, Brakeman PR. Renal repair and recovery. Crit Care Med. Apr 2008;36(4 Suppl):S187-92. doi:10.1097/CCM.0b013e318168ca4a

16. Mori K, Nakao K. Neutrophil gelatinase-associated lipocalin as the real-time indicator of active kidney damage. Kidney Int. May 2007;71(10):967-70. doi:10.1038/sj.ki.5002165 
17. Haase M, Bellomo R, Devarajan P, Schlattmann P, Haase-Fielitz A. Accuracy of neutrophil gelatinase-associated lipocalin (NGAL) in diagnosis and prognosis in acute kidney injury: a systematic review and meta-analysis. Am J Kidney Dis. Dec 2009;54(6):1012-24. doi:10.1053/j.ajkd.2009.07.020

18. Haase-Fielitz A, Bellomo R, Devarajan P, et al. Novel and conventional serum biomarkers predicting acute kidney injury in adult cardiac surgery-a prospective cohort study. Crit Care Med. Feb 2009;37(2):553-60. doi:10.1097/CCM.0b013e318195846e

19. Hall PS, Mitchell ED, Smith AF, et al. The future for diagnostic tests of acute kidney injury in critical care: evidence synthesis, care pathway analysis and research prioritisation. Health Technol Assess. May 2018;22(32):1-274. doi:10.3310/hta22320

20. Brazzelli M, Aucott L, Aceves Martins M, et al. The ARCHITECT and Alinity urine NGAL assays, urine NephroCheck test, and urine and plasma NGAL tests to help assess the risk of acute kidney injury for people who are being considered for admission to critical care. 2019.

21. Page MJ, McKenzie JE, Bossuyt PM, et al. The PRISMA 2020 statement: An updated guideline for reporting systematic reviews. Int J Surg. Apr 2021;88:105906. doi:10.1016/j.ijsu.2021.105906

22. Khwaja A. KDIGO clinical practice guidelines for acute kidney injury. Nephron Clin Pract. 2012;120(4):c179-84. doi:10.1159/000339789

23. Bellomo R, Ronco C, Kellum JA, Mehta RL, Palevsky P. Acute renal failure - definition, outcome measures, animal models, fluid therapy and information technology needs: the Second International Consensus Conference of the Acute Dialysis Quality Initiative (ADQI) Group. Crit Care. Aug 2004;8(4):R204-12. doi:10.1186/cc2872

24. Mehta RL, Kellum JA, Shah SV, et al. Acute Kidney Injury Network: report of an initiative to improve outcomes in acute kidney injury. Crit Care. 2007:R31. vol. 2.

25. Whiting PF, Rutjes AW, Westwood ME, et al. QUADAS-2: a revised tool for the quality assessment of diagnostic accuracy studies. Ann Intern Med. Oct 18 2011;155(8):529-36. doi:10.7326/0003-4819-155-8-201110180-00009

26. Macaskill P, Gatsonis C, Deeks JJ, Harbord RM T, Y. a. Chapter 10: Analysing and Presenting Results. In: Deeks JJ BP, Gatsonis C, ed. Cochrane Handbook for Systematic Reviews of Diagnostic Test Accuracy Version 10. The Cochrane Collaboration; 2010:chap 10.

27. Higgins JP, Thompson SG, Deeks JJ, Altman DG. Measuring inconsistency in meta-analyses. Bmj. Sep 6 2003;327(7414):557-60. doi:10.1136/bmj.327.7414.557

28. Othman HMEDM, Hassan AEM, Elsersi MH, Soliman AKMA, Emam DF. Neutrophil gelatinase-associated lipocalin as a biomarker for predicting acute kidney injury after coronary artery bypass grafting. Ain-Shams Journal of Anesthesiology. 2021/01/20 2021;13(1):5. doi:10.1186/s42077-020-00123-5

29. Parikh CR, Coca SG, Thiessen-Philbrook H, et al. Postoperative biomarkers predict acute kidney injury and poor outcomes after adult cardiac surgery. J Am Soc Nephrol. Sep 2011;22(9):1748-57. doi:10.1681/asn.2010121302

30. Ghonemy TA, Amro GM. Plasma neutrophil gelatinase-associated lipocalin (NGAL) and plasma cystatin C (CysC) as biomarker of acute kidney injury after cardiac surgery. Saudi J Kidney Dis Transpl. May 2014;25(3):582-8. doi:10.4103/1319-2442.132194

31. Thakar CV, Arrigain S, Worley S, Yared JP, Paganini EP. A clinical score to predict acute renal failure after cardiac surgery. $J$ Am Soc Nephrol. Jan 2005;16(1):162-8. doi:10.1681/asn.2004040331

32. Seabra VF, Alobaidi S, Balk EM, Poon AH, Jaber BL. Off-pump coronary artery bypass surgery and acute kidney injury: a metaanalysis of randomized controlled trials. Clin J Am Soc Nephrol. Oct 2010;5(10):1734-44. doi:10.2215/cjn.02800310

33. Kjeldsen L, Johnsen AH, Sengeløv H, Borregaard N. Isolation and primary structure of NGAL, a novel protein associated with human neutrophil gelatinase. J Biol Chem. May 15 1993;268(14):10425-32.

34. Kjeldsen L, Bainton DF, Sengeløv H, Borregaard N. Identification of neutrophil gelatinase-associated lipocalin as a novel matrix protein of specific granules in human neutrophils. Blood. Feb 1 1994;83(3):799-807.

35. Xu SY, Carlson M, Engström A, Garcia R, Peterson CG, Venge P. Purification and characterization of a human neutrophil lipocalin (HNL) from the secondary granules of human neutrophils. Scand J Clin Lab Invest. Aug 1994;54(5):365-76. doi:10.3109/00365519409088436

36. Cai L, Rubin J, Han W, Venge P, Xu S. The origin of multiple molecular forms in urine of HNL/NGAL. Clin J Am Soc Nephrol. Dec 2010;5(12):2229-35. doi:10.2215/cjn.00980110

37. Liu KD, Thompson BT, Ancukiewicz M, et al. Acute kidney injury in patients with acute lung injury: impact of fluid accumulation on classification of acute kidney injury and associated outcomes. Crit Care Med. Dec 2011;39(12):2665-71.

Page $12 / 21$ 
doi:10.1097/CCM.0b013e318228234b

38. Haase M, Devarajan P, Haase-Fielitz A, et al. The outcome of neutrophil gelatinase-associated lipocalin-positive subclinical acute kidney injury: a multicenter pooled analysis of prospective studies. J Am Coll Cardiol. Apr 26 2011;57(17):1752-61. doi:10.1016/j.jacc.2010.11.051

39. Nickolas TL, Schmidt-Ott KM, Canetta P, et al. Diagnostic and prognostic stratification in the emergency department using urinary biomarkers of nephron damage: a multicenter prospective cohort study. J Am Coll Cardiol. Jan 17 2012;59(3):246-55. doi:10.1016/j.jacc.2011.10.854

40. Deeks JJ, Macaskill P, Irwig L. The performance of tests of publication bias and other sample size effects in systematic reviews of diagnostic test accuracy was assessed. J Clin Epidemiol. Sep 2005;58(9):882-93. doi:10.1016/j.jclinepi.2005.01.016

41. NICE. Diagnostics Assessment Programme Manual. NICE; 2011. December 2011. https://www.nice.org.uk/Media/Default/About/what-we-do/NICE-guidance/NICE-diagnostics-guidance/Diagnostics-assessmentprogramme-manual.pdf

42. Merkle J, Daka A, Deppe AC, Wahlers T, Paunel-Görgülü A. High levels of cell-free DNA accurately predict late acute kidney injury in patients after cardiac surgery. PLoS One. 2019;14(6):e0218548. doi:10.1371/journal.pone.0218548

43. Introcaso G, Nafi M, Bonomi A, et al. Improvement of neutrophil gelatinase-associated lipocalin sensitivity and specificity by two plasma measurements in predicting acute kidney injury after cardiac surgery. Biochem Med (Zagreb). Oct 15 2018;28(3):030701. doi:10.11613/bm.2018.030701

44. Guerci P, Claudot JL, Novy E, Settembre N, Lalot JM, Losser MR. Immediate postoperative plasma neutrophil gelatinase-associated lipocalin to predict acute kidney injury after major open abdominal aortic surgery: A prospective observational study. Anaesth Crit Care Pain Med. Aug 2018;37(4):327-334. doi:10.1016/j.accpm.2017.09.006

45. Schley G, Köberle C, Manuilova E, et al. Comparison of Plasma and Urine Biomarker Performance in Acute Kidney Injury. PLoS One. 2015;10(12):e0145042. doi:10.1371/journal.pone.0145042

46. Park CM, Kim JS, Moon HW, et al. Usefulness of plasma neutrophil gelatinase-associated lipocalin as an early marker of acute kidney injury after cardiopulmonary bypass in Korean cardiac patients: a prospective observational study. Clin Biochem. Jan 2015;48(1-2):44-9. doi:10.1016/j.clinbiochem.2014.09.019

47. Kidher E, Harling L, Ashrafian H, et al. Pulse wave velocity and neutrophil gelatinase-associated lipocalin as predictors of acute kidney injury following aortic valve replacement. J Cardiothorac Surg. May 17 2014;9:89. doi:10.1186/1749-8090-9-89

48. Perry TE, Muehlschlegel JD, Liu KY, et al. Plasma neutrophil gelatinase-associated lipocalin and acute postoperative kidney injury in adult cardiac surgical patients. Anesth Analg. Jun 1 2010;110(6):1541-7. doi:10.1213/ANE.0b013e3181da938e

49. Haase M, Bellomo R, Devarajan P, et al. Novel biomarkers early predict the severity of acute kidney injury after cardiac surgery in adults. Ann Thorac Surg. Jul 2009;88(1):124-30. doi:10.1016/j.athoracsur.2009.04.023

50. Perrotti A, Miltgen G, Chevet-Noel A, et al. Neutrophil gelatinase-associated lipocalin as early predictor of acute kidney injury after cardiac surgery in adults with chronic kidney failure. Ann Thorac Surg. Mar 2015;99(3):864-9.

doi:10.1016/j.athoracsur.2014.10.011

51. Gaipov A, Solak Y, Turkmen K, et al. Serum uric acid may predict development of progressive acute kidney injury after open heart surgery. Ren Fail. Feb 2015;37(1):96-102. doi:10.3109/0886022x.2014.976130

52. Prabhu A, Sujatha DI, Ninan B, Vijayalakshmi MA. Neutrophil gelatinase associated lipocalin as a biomarker for acute kidney injury in patients undergoing coronary artery bypass grafting with cardiopulmonary bypass. Ann Vasc Surg. May 2010;24(4):525-31. doi:10.1016/j.avsg.2010.01.001

53. Tuladhar SM, Püntmann VO, Soni M, Punjabi PP, Bogle RG. Rapid detection of acute kidney injury by plasma and urinary neutrophil gelatinase-associated lipocalin after cardiopulmonary bypass. J Cardiovasc Pharmacol. Mar 2009;53(3):261-6. doi:10.1097/FJC.0b013e31819d6139

\section{Figures}



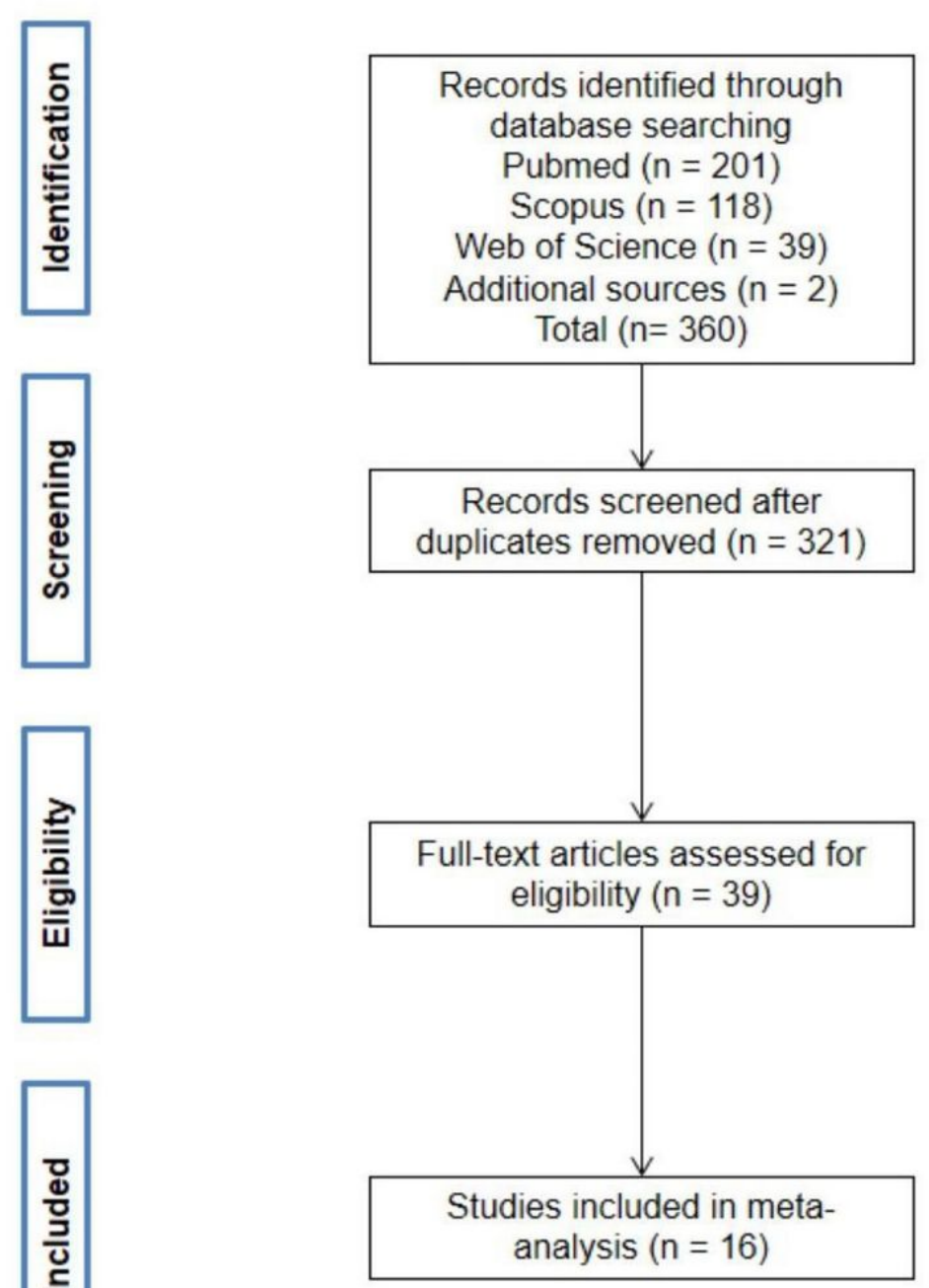

\section{Figure 1}

Flow of studies through the selection process

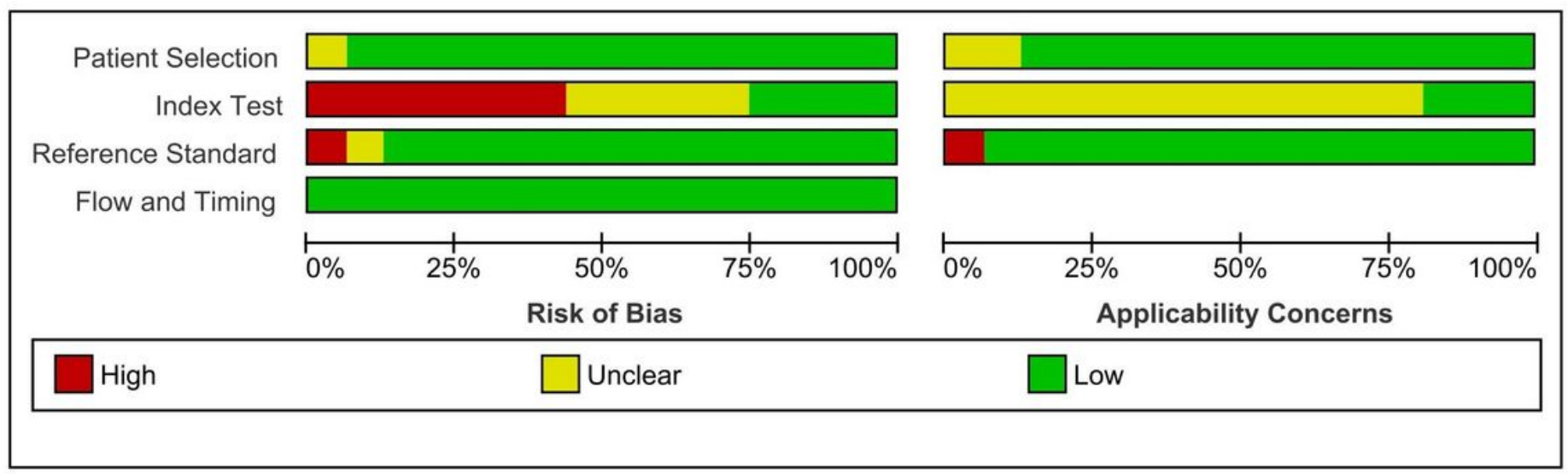

Figure 2 


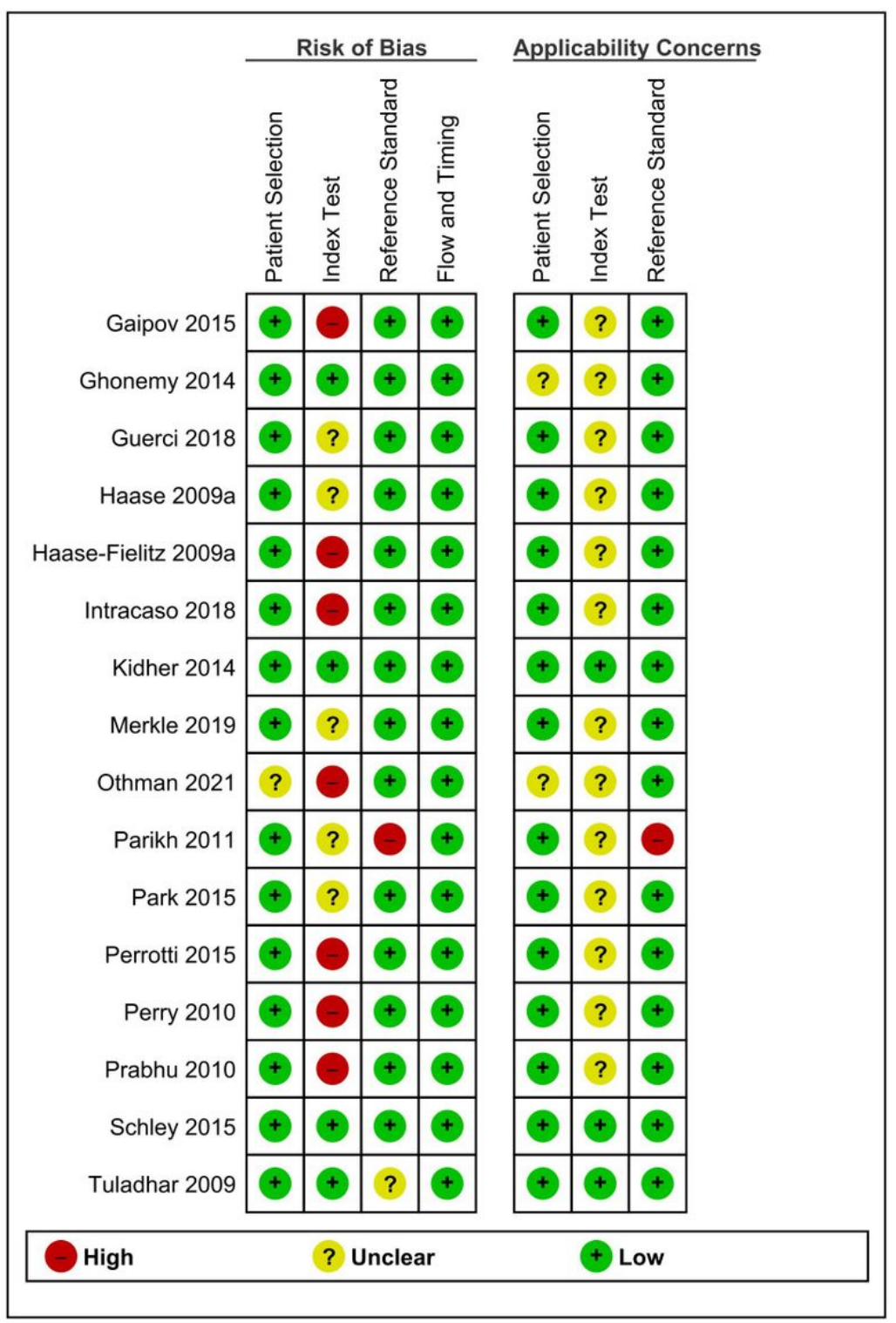

Figure 3

Risk of bias assessment using the QUADAS-2 tool: individual study summary 
Plasma NGAL $<4 \mathrm{hr}$

$\begin{array}{lrrrrrr}\text { Study } & \text { TP } & \text { FP } & \text { FN } & \text { TN } & \text { Sensitivity }(95 \% \text { CI) } & \text { Specificity }(95 \% \text { CI) } \\ \text { Ghonemy 2014 } & 16 & 2 & 1 & 31 & 0.94[0.71,1.00] & 0.94[0.80,0.99] \\ \text { Kidher 2014 } & 13 & 4 & 3 & 33 & 0.81[0.54,0.96] & 0.89[0.75,0.97] \\ \text { Merkle 2019 } & 15 & 3 & 6 & 34 & 0.71[0.48,0.89] & 0.92[0.78,0.98] \\ \text { Parikh 2011 } & 30 & 209 & 30 & 950 & 0.50[0.37,0.63] & 0.82[0.80,0.84] \\ \text { Perrotti 2015 } & 28 & 33 & 24 & 81 & 0.54[0.39,0.68] & 0.71[0.62,0.79] \\ \text { Perry 2010 } & 29 & 149 & 46 & 655 & 0.39[0.28,0.51] & 0.81[0.79,0.84] \\ \text { Schley 2015 } & 28 & 18 & 9 & 55 & 0.76[0.59,0.88] & 0.75[0.64,0.85] \\ \text { Tuladhar 2009 } & 7 & 14 & 2 & 27 & 0.78[0.40,0.97] & 0.66[0.49,0.80]\end{array}$

Plasma NGAL 4-8 hr

$\begin{array}{lrrrrrr}\text { Study } & \text { TP } & \text { FP } & \text { FN } & \text { TN } & \text { Sensitivity }(95 \% \text { CI) } & \text { Specificity }(95 \% \text { CI) } \\ \text { Ghonemy 2014 } & 17 & 3 & 0 & 30 & 1.00[0.80,1.00] & 0.91[0.76,0.98] \\ \text { Guerci 2018 } & 15 & 5 & 3 & 27 & 0.83[0.59,0.96] & 0.84[0.67,0.95] \\ \text { Haase 2009a } & 34 & 14 & 12 & 40 & 0.74[0.59,0.86] & 0.74[0.60,0.85] \\ \text { Haase-Fielitz 2009a } & 18 & 17 & 5 & 60 & 0.78[0.56,0.93] & 0.78[0.67,0.87] \\ \text { Intracaso 2018 } & 18 & 18 & 6 & 27 & 0.75[0.53,0.90] & 0.60[0.44,0.74] \\ \text { Othman 2021 } & 7 & 2 & 0 & 16 & 1.00[0.59,1.00] & 0.89[0.65,0.99] \\ \text { Park 2015 } & 8 & 11 & 5 & 88 & 0.62[0.32,0.86] & 0.89[0.81,0.94] \\ \text { Perrotti 2015 } & 41 & 48 & 11 & 66 & 0.79[0.65,0.89] & 0.58[0.48,0.67] \\ \text { Prabhu 2010 } & 8 & 2 & 0 & 20 & 1.00[0.63,1.00] & 0.91[0.71,0.99] \\ \text { Schley 2015 } & 29 & 18 & 8 & 55 & 0.78[0.62,0.90] & 0.75[0.64,0.85]\end{array}$

Plasma NGAL $12 \mathrm{hr}$

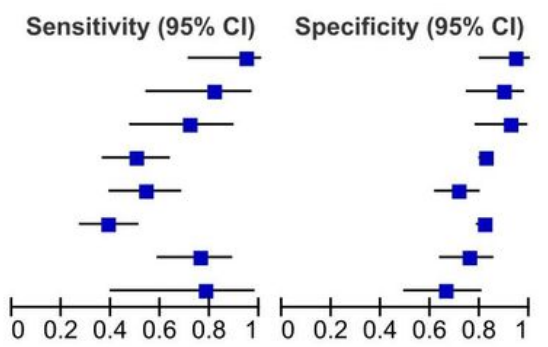

Sensitivity $(95 \% \mathrm{CI}) \quad$ Specificity $(95 \% \mathrm{Cl})$

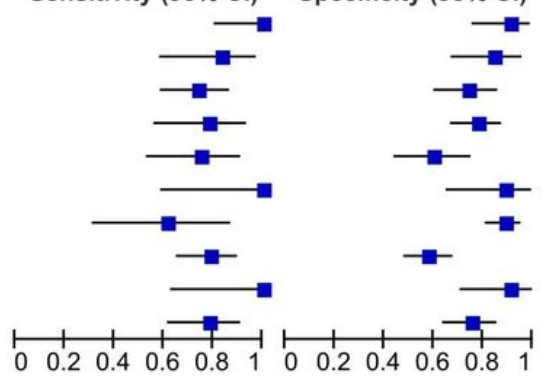

Study TP FP FN TN Sensitivity $(95 \% \mathrm{CI})$ Specificity $(95 \% \mathrm{CI})$

Gaipov $2015 \quad 21 \quad 5 \quad 19 \quad 15 \quad 0.53[0.36,0.68] \quad 0.75[0.51,0.91]$

$\begin{array}{llllll}\text { Perrotti } 2015 \quad 43 & 48 & 9 & 66 & 0.83[0.70,0.92] & 0.58[0.48,0.67]\end{array}$

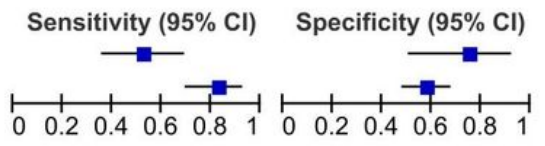

Plasma NGAL $24 \mathrm{hr}$

\begin{tabular}{|c|c|c|c|c|c|c|c|c|}
\hline Study & TP & FP & FN & TN & Sensitivity $(95 \% \mathrm{CI})$ & Specificity $(95 \% \mathrm{Cl})$ & Sensitivity $(95 \% \mathrm{CI})$ & Specificity $(95 \% \mathrm{CI})$ \\
\hline Gaipov 2015 & 32 & 11 & 8 & 9 & $0.80[0.64,0.91]$ & $0.45[0.23,0.68]$ & & \\
\hline Haase-Fielitz 2009a & 21 & 18 & 2 & 59 & $0.91[0.72,0.99]$ & $0.77[0.66,0.86]$ & & \\
\hline Merkle 2019 & 18 & 8 & 3 & 29 & $0.86[0.64,0.97]$ & $0.78[0.62,0.90]$ & & \\
\hline Perrotti 2015 & 31 & 27 & 21 & 87 & $0.60[0.45,0.73]$ & $0.76[0.67,0.84]$ & & \\
\hline Perry 2010 & 42 & 242 & 33 & 562 & $0.56[0.44,0.67]$ & $0.70[0.67,0.73]$ & & 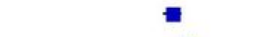 \\
\hline Schley 2015 & 32 & 18 & 5 & 55 & $0.86[0.71,0.95]$ & $0.75[0.64,0.85]$ & $\begin{array}{llll}0.2 & 0.4 & 0.6 & 0.8\end{array}$ & $\frac{1}{0.60 .8}$ \\
\hline
\end{tabular}

Figure 4

Forest plots of all studies categorised by time post CPB cessation 
a)

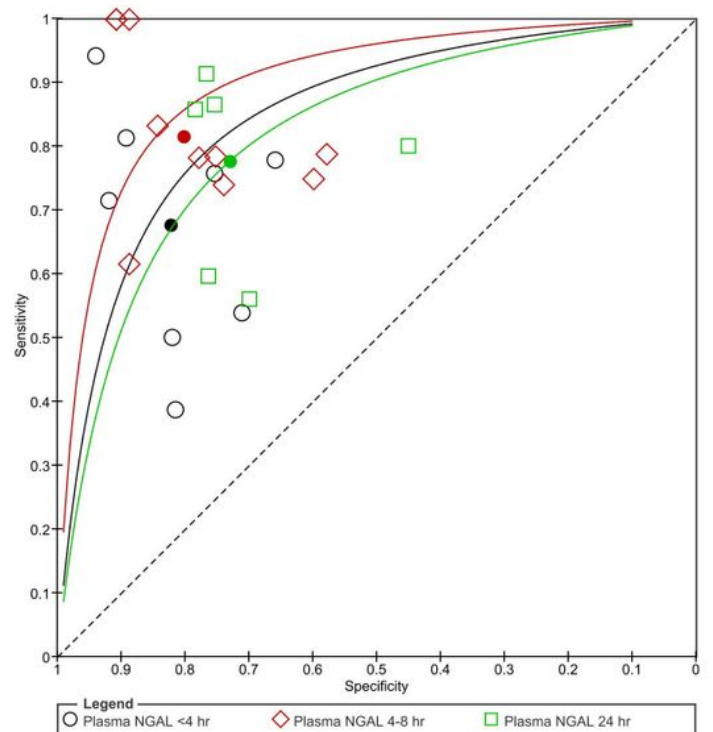

b)

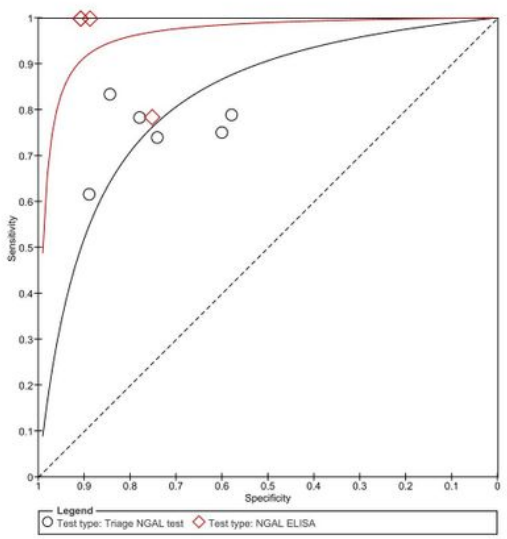

c)

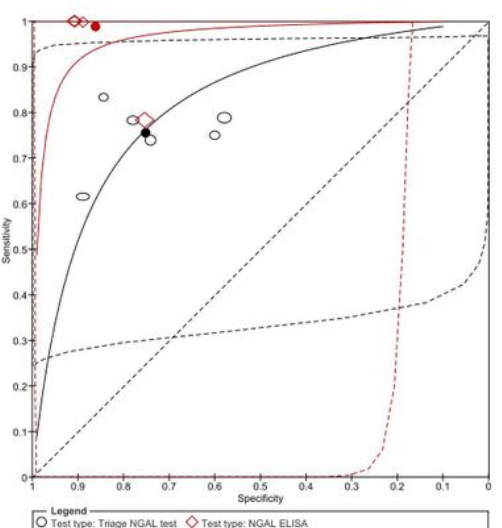

\section{Figure 5}

a) summary ROC plots with hSROC summary points overlaid, b) summary ROC when method type was added as a covariate, c) summary ROC when method type was added as a covariate with hSROC summary points and prediction regions overlaid. 


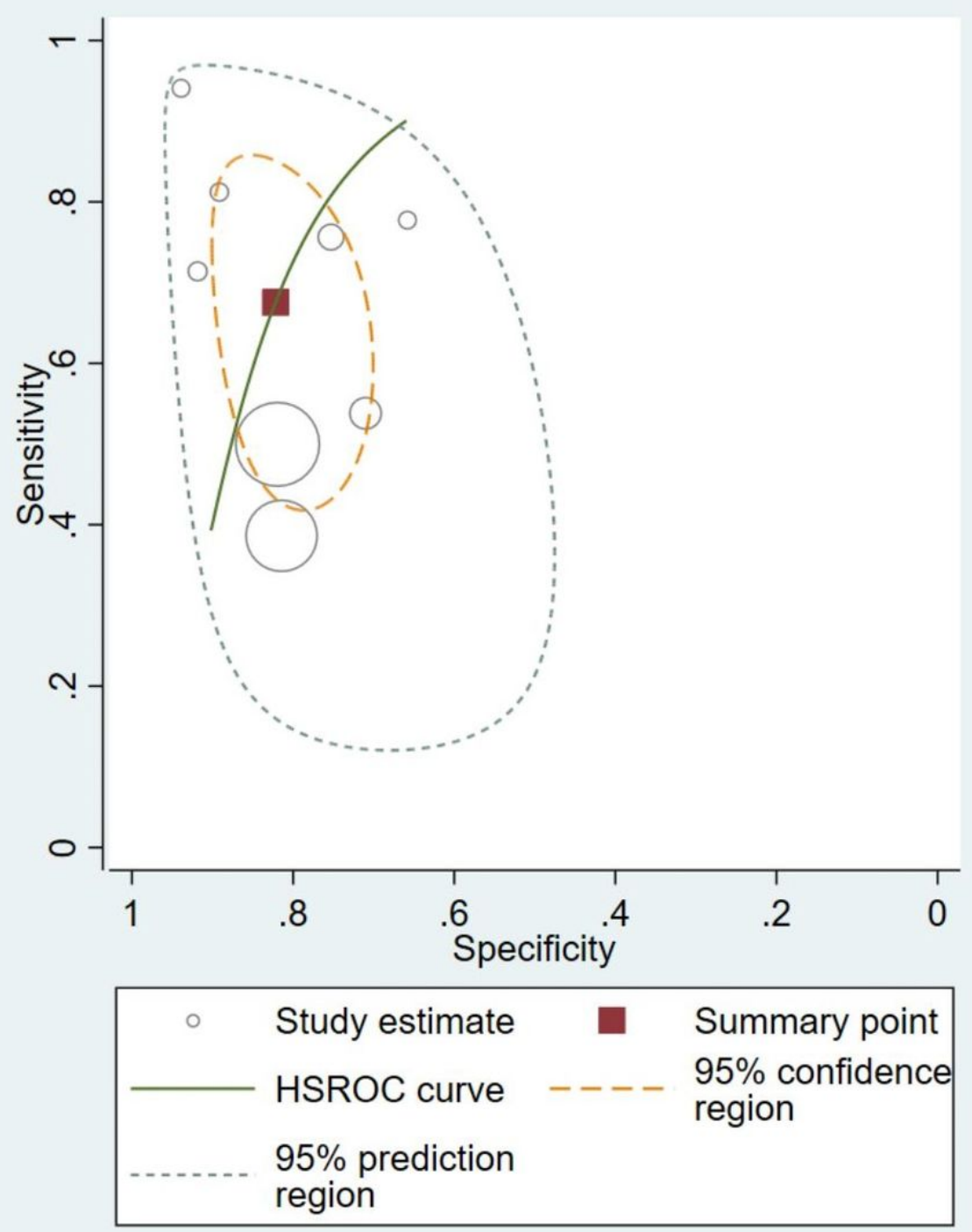

Figure 6

hSROC of pNGAL taken at $<4$ hours post CPB 
a)
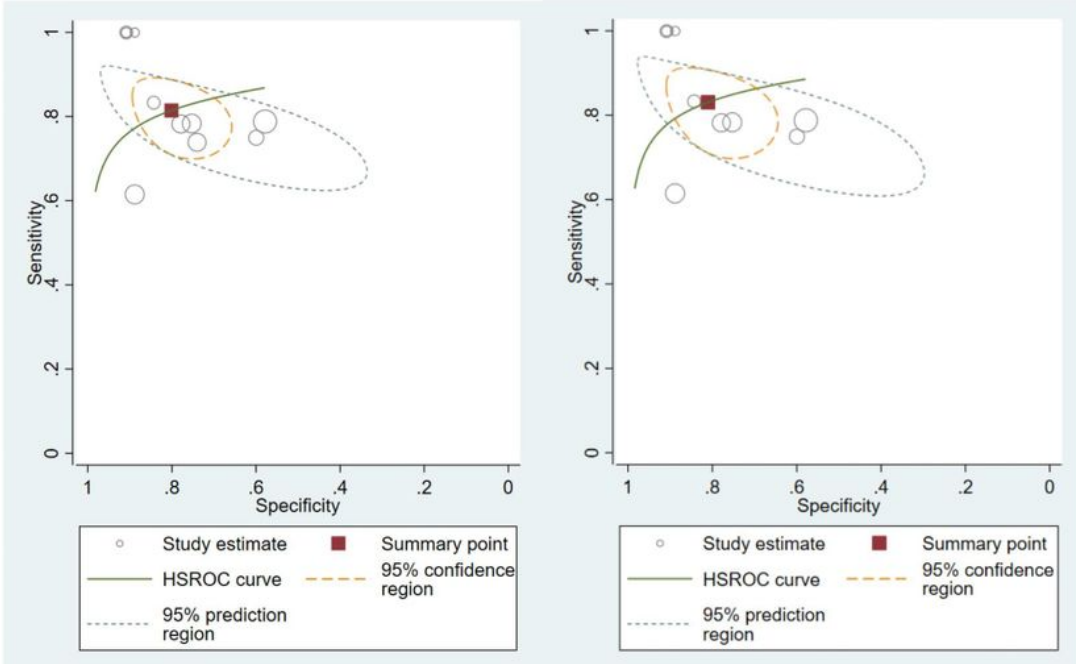

b)
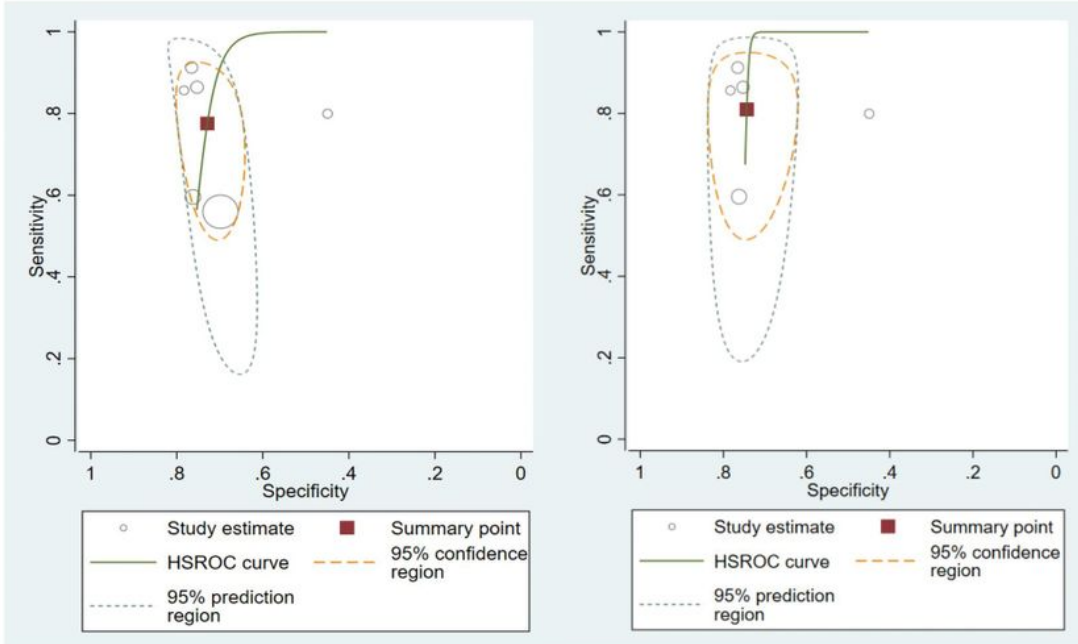

Figure 7

a) hSROC of pNGAL taken at 4-8 hours post CPB: left hSROC including all studies and right hSROC following removal of Haase, 2009 study due to possible incorrect subgrouping b) hSROC of pNGAL taken at 24 hours post CPB: left hSROC including all studies and right hSROC following removal of Perry, 2010 study due to high risk of bias 


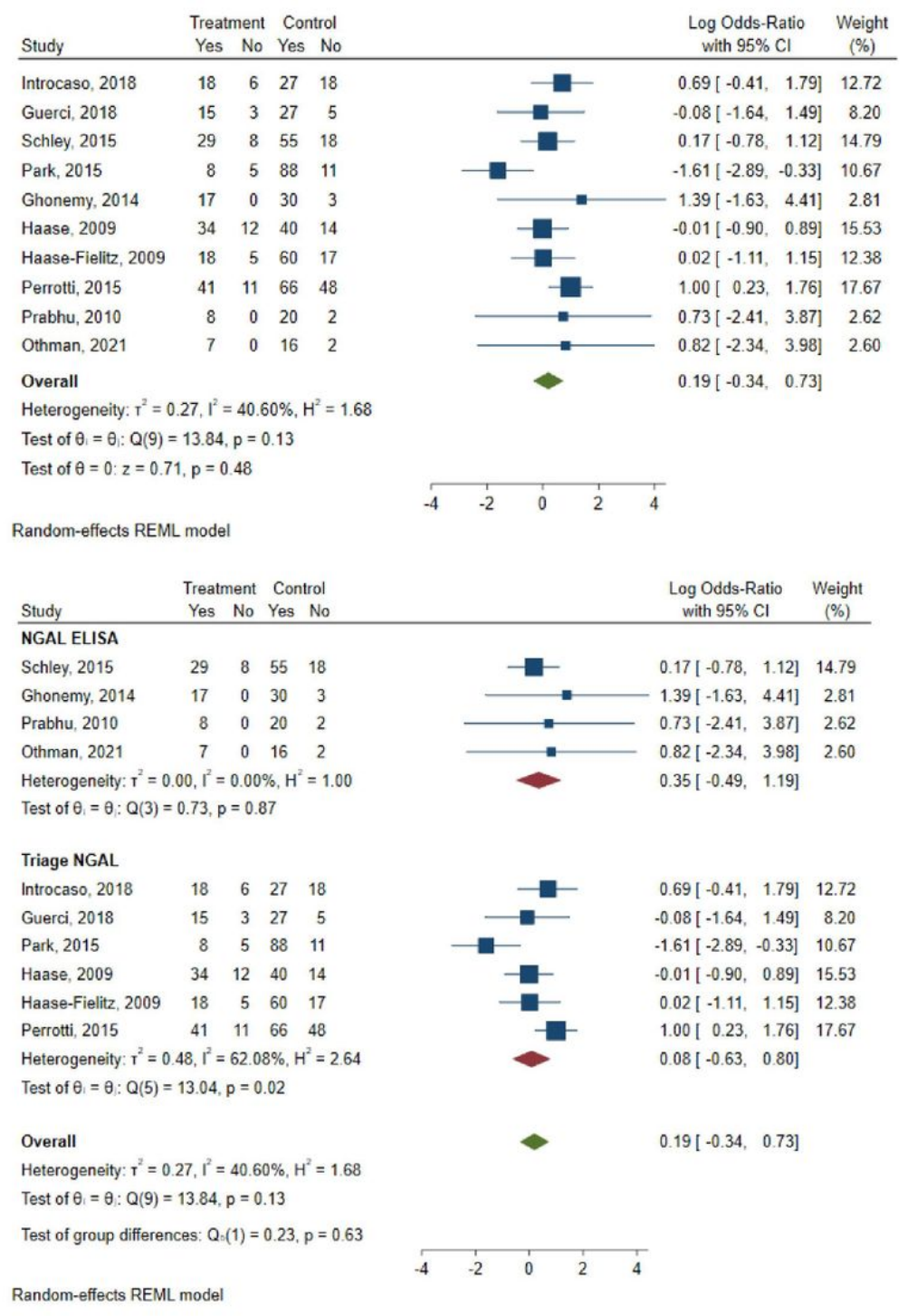

\section{Figure 8}

Random effects- meta-analysis of odds ratios and subgroup analysis in the 4-8 hour group 


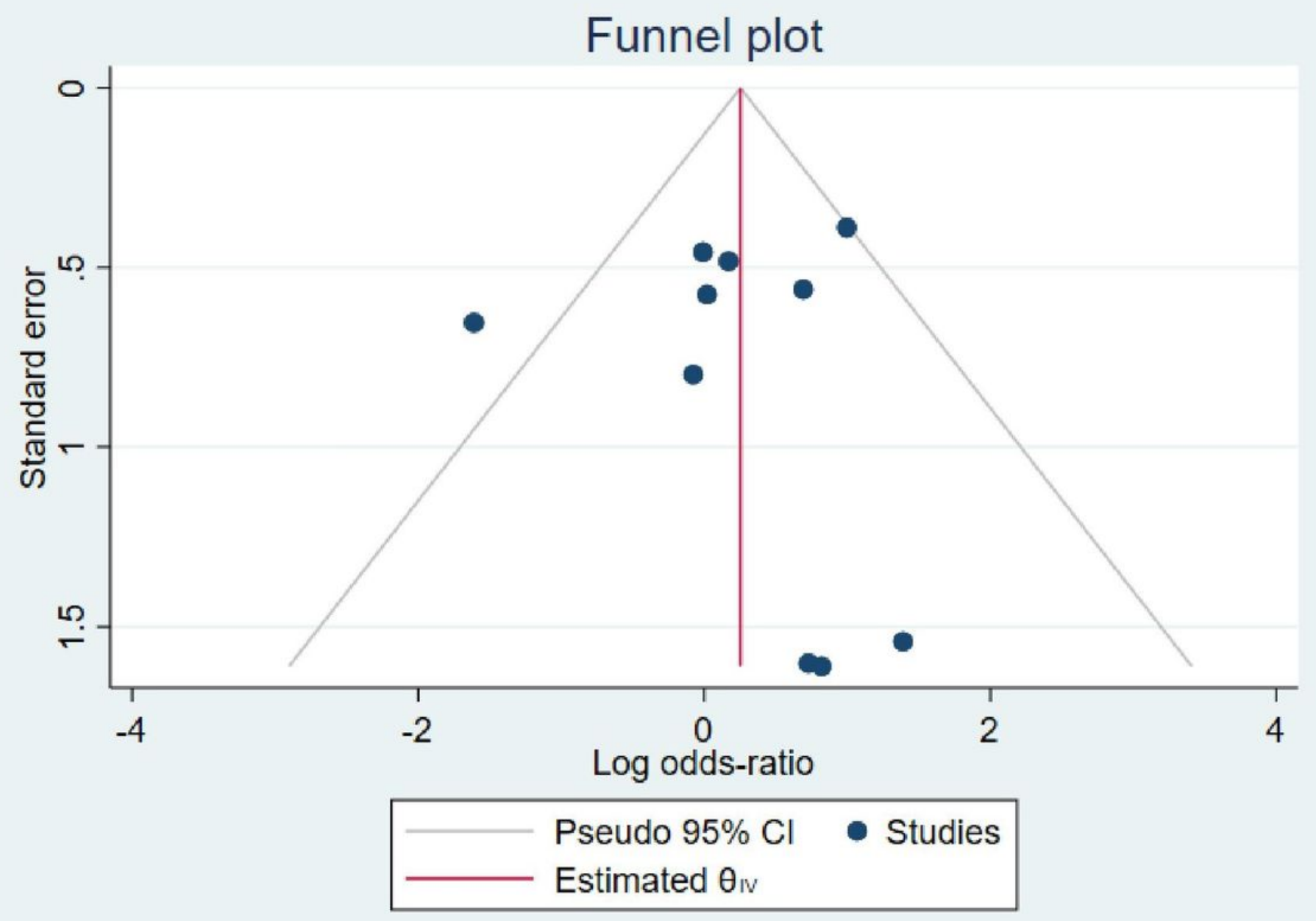

Figure 9

Funnel plot of effect size versus standard error in the 4-8 hour group

\section{Supplementary Files}

This is a list of supplementary files associated with this preprint. Click to download.

- PRISMA2020checklist2.docx 